\title{
Implantable Cardioverter-Defibrillator of Korean Patients in a Single Center Registry
}

Jin Kyung Hwang, MD, PhD; Hye Bin Gwag, MD; Seung-Jung Park, MD, PhD; Kyoung-min Park MD, PhD; June Soo Kim, MD, PhD; Young Keun On, MD, PhD

Division of Cardiology, Department of Medicine, Samsung Medical Center, Sungkyunkwan University School of Medicine, Seoul, Republic of Korea
Received: October 16, 2017

Revision Received: November 1, 2017 Accepted: November 4, 2017

Correspondence: Young Keun On, MD PhD

Division of Cardiology, Department of Medicine

81 Irwon-ro, Gangnam-gu, Seoul 06351, Republic of Korea

Tel: +82-2-3410-3420 FAX: +82-2-3410-3849

E-mail: yk.on@samsung.com, oykmd123@gmail.com

Copyright (C) 2017 The Official Journal of Korean Heart Rhythm Society Editorial Board and EUM \& Communication

\begin{abstract}
Background and Objectives: The safety and efficacy of implantable cardioverter-defibrillator (ICD) for Korean is unclear. We investigated the clinical characteristics and outcomes of Korean patients undergoing ICD for primary or secondary prevention.
\end{abstract}

Materials and Methods: From October 1999 to December 2016, 396 cases (365 patients) of ICD implantation were performed: Baseline characteristics, procedural findings, and clinical outcome data were collected retrospectively from our ICD registry. The primary outcome was composite of cardiac death, appropriate shock or antitachycardia pacing.

Results: Among 365 patients, 91 patients (25.9\%) had ICD for primary prevention and 274 patients $(75.1 \%)$ were for secondary prevention ( $51.2 \pm 17.10$ years, male was $80.8 \%)$. The median follow-up period was 3.1 years (interquartile range: 1.6-6.0 days). The most prevalent etiology was dilated cardiomyopathy $(46.2 \%)$ in the primary prevention and idiopathic ventricular tachycardia or fibrillation $(24.4 \%)$ in the secondary prevention. The primary outcome was noted in $28.6 \%$ of the primary prevention and $33.2 \%$ of the secondary prevention $(P=0.44)$. The rate of cardiac death was $2.2 \%$ in the primary prevention and $1.8 \%$ in the secondary prevention $(P=1.00)$. The hospitalization due to heart failure was higher in the primary prevention compared with the secondary prevention $(23.1 \%$ versus $13.5 \%, P=0.03)$. ICD therapy occurred in 134 patients (36.7\%). Among them, 60 patients (44.8\% of ICD therapy) experienced inappropriate shock. The most common cause of inappropriate shock was atrial fibrillation of flutter (AF/AFL).

Conclusion: The clinical efficacy and safety of ICD in Korean is consistent with the data from Western countries.

Key Words: - Implantable Cardioverter Defibrillator - Korean - Etiology - Cardiac Death - Shock 


\section{Introduction}

Annually, 500,000 people experience sudden cardiac death

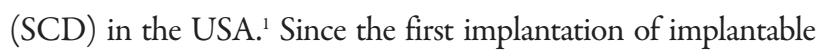
cardioverter-defibrillator (ICD) in 1980, cardiac care in high-risk patients with potentially life-threatening arrhythmias has significantly changed. Large-scale clinical trials clearly demonstrated that the ICD increases survival rates in selected patients, with a $30 \%$ to $50 \%$ reduction in mortality risk. ${ }^{2.4}$ In these randomized controlled studies, the efficacy of ICD for the primary prevention of SCD has been established. An observational study has also reported similar results for primary prevention that were observed in randomized controlled trials. ${ }^{5}$ Although research on the efficacy of ICD for secondary prevention is limited, recent guidelines recommend consideration of an ICD implantation for either primary or secondary prevention in selected patients. ${ }^{6,7}$ For this reason, ICD implantation is widely performed in developed countries despite its high cost. Studies conducted to date have involved mostly Westerners, with only a few Asians being included.

In Korea, ICD has been available since the 1990s. Although the safety and efficacy of ICDs have been substantiated in patients from Western countries, only a few studies have proven its safety and efficacy in Korean patients. ${ }^{8,9}$ Therefore, we retrospectively reviewed the experience of patients with ICDs in our center and evaluated the clinical efficacy of ICD implantation in Korean patients.

\section{Methods}

\section{Study population}

From October 1999 to December 2016, ICD implantation was performed in 396 cases (365 patients) in Samsung Medical Center, Seoul, Korea (Figure 1). The initial implantation of ICD system was performed in 357 cases (357 patients). Generator change for elective replacement interval was performed in 28 cases, 22 of whom were initially implanted with ICD in our center, 2 experienced generator change twice, and 4 were implanted with ICD in another center. Lead reposition immediately after initial implantation was performed in 3 cases.

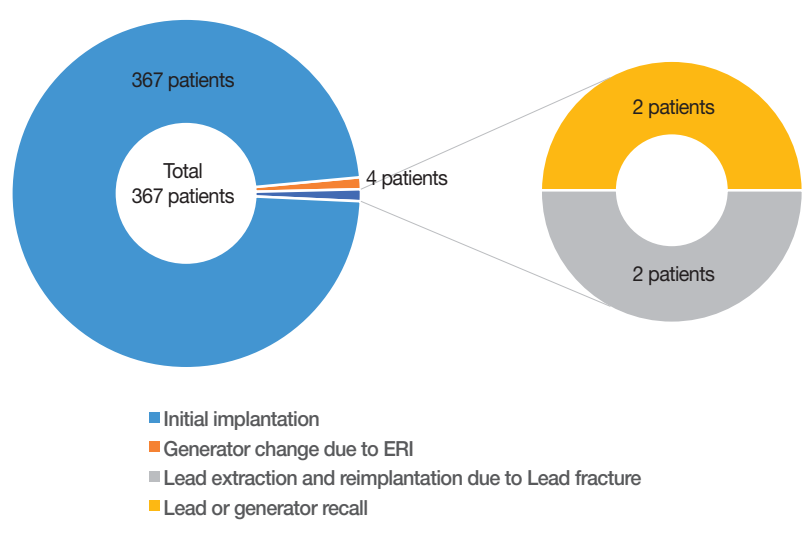

Figure 1. Procedural characteristics of study patients ERI, electrive replacement interval

Reimplantation of ICD system was also performed in 3 cases because of ICD system infection. Either lead or generator was changed in 2 cases for Riata lead recall, 2 cases for lead fracture, and 1 case for generator recall. All procedures were performed using standard techniques. All decisions about ICD implantation were based on contemporary guidelines. ${ }^{6,7}$ Baseline characteristics, procedural findings, and clinical outcome data were collected retrospectively from the medical records in our ICD registry by research coordinators. All procedures were performed in accordance with the institutional guidelines of Samsung Medical Center, and all patients waived their written informed consent.

\section{ICD devices and programming}

All commercially available devices approved by the Korea Food \& Drug Administration were implanted. The use of singlechamber or dual-chamber and single-coil or dual-coil ICDs depended on the preference of physicians. The ICD programming, including discriminator usage, also depended on the discretion of physicians. The therapy zone was divided into three zones (VF zone, VT2 zone, and VT1 zone), and the total number of zones where ICD therapy was set was counted for categorization.

\section{ICD therapy event analysis}

The ICDs were interrogated every 3-4 months after 
implantation and after a shock event. A technical specialist of the electrocardiogram (ECG) core laboratory analyzed the rhythm triggering antitachycardia pacing (ATP) or shock using the stored ECG, and an electrophysiologist confirmed the rhythm again. Either ATP or shock was defined as an ICD therapy. All ICD therapies not triggered by ventricular tachycardia or fibrillation (VT/VF) were defined as an inappropriate therapy. The probable cause of inappropriate therapy was categorized using the following published criteria: atrial fibrillation or flutter (AF/AFL); supraventricular tachycardia (SVT), including sinus tachycardia; or inappropriate sensing such as $\mathrm{T}$ wave oversensing and noise. ${ }^{10,11}$ The termination of arrhythmia was defined as either ICD re-detecting sinus rhythm or rate down below the detection. Every ICD therapy recorded in the memory was counted.

\section{Definition of clinical events}

The primary outcome was defined as a composite of cardiac death, appropriate shock, or ATP. The secondary outcomes were all-cause death, cardiac death, heart failure admission, heart transplantation, pocket infection, incidence of appropriate and inappropriate therapy, and total event number of appropriate and inappropriate therapy during follow-up period. All deaths were considered cardiac deaths unless a definite noncardiac cause could be established. Hospitalization because of heart failure aggravation or shock event that terminated in death during the same hospital stay was considered a death event. ICD infection was defined as the case of antibiotic treatment due to the rise of white blood count or C-reactive protein accompanied by erythema of pocket area or erosion.

\section{Statistical analysis}

Continuous variables were presented as mean \pm standard deviation, and differences were assessed by independent $t$-test or Wilcoxon rank sum test. Categorical variables were described as a number $(\mathrm{n})$ with percentage (\%). To analyze the differences, Pearson $\chi^{2}$ or Fisher's exact test was used. Survival curves were constructed using Kaplan-Meier estimates of the time to the first event and subsequently compared using a log-rank test. The Cox proportional hazards model was used to compare the risks of clinical outcomes. Covariates that were statistically significant on univariate analysis and/or those that were clinically relevant in the multivariate analysis were included. A $p$-value of $<0.05$ was considered to be statistically significant. All statistical analyses were conducted by means of 2-tailed tests using SPSS version 18.0 software (SPSS Inc., Chicago, IL).

\section{Results}

\section{Demographic and clinical characteristics}

A total of 365 patients with ICD for primary or secondary prevention were analyzed in the study. The patient's baseline characteristics were categorized based on the intention of ICD implantation. Table 1 shows the baseline characteristics of the patients. Among the 365 patients, 91 (24.9\%) and 274 patients (75.1\%) had ICD for primary and secondary prevention, respectively. The ages of patients with ICD for primary and secondary prevention were $55.4 \pm 14.48$ years and $49.80 \pm 17.70$ years, respectively. ICD implantation was most commonly performed in those aged 50 years, with age being normally distributed (Figure 2A). The number of patients undergoing ICD implantation has steadily increased in the twenty-first century, increasing dramatically since 2011 (Figure 2B). More patients with ICD for primary prevention had a family history of SCD and dyslipidemia than those with ICD for secondary prevention. New York Heart Association (NYHA) functional class II heart failure was the most prevalent condition in both groups $(56.0 \%$ and $61.7 \%$ in the primary and secondary prevention respectively). Atrial fibrillation (AF) was present in $31.9 \%$ and $28.1 \%$ of the patients with ICD for primary and secondary prevention, respectively, who had left ventricular ejection fractions of $34.7 \% \pm 14.67 \%$ and $39.7 \% \pm 15.86 \%$, respectively. The most common etiologies for ICD implantation were dilated cardiomyopathy (CMP) (46.2\%) and idiopathic VT/VF (24.4\%) in the patients with ICD for primary and secondary prevention, respectively. Coronary artery disease was the second most common cause in both groups $(26.4 \%$ and $23.7 \%$, respectively). 
Table 1. Baseline characteristics of patients

\begin{tabular}{|c|c|c|c|c|}
\hline & $\begin{array}{c}\text { Total } \\
(\mathrm{n}=365)\end{array}$ & $\begin{array}{l}\text { Primary prevention } \\
\quad(n=91)\end{array}$ & $\begin{array}{l}\text { Secondary prevention } \\
(\mathrm{n}=274)\end{array}$ & $P$-value \\
\hline Male & $295(80.8)$ & $73(80.2)$ & $222(81.0)$ & 0.88 \\
\hline Age (years) & $51.2 \pm 17.10$ & $55.4 \pm 14.5$ & $49.8 \pm 17.70$ & 0.01 \\
\hline BMI & $23.5 \pm 3.78$ & $43.0 \pm 3.27$ & $23.3 \pm 3.93$ & 0.05 \\
\hline Family history of SCD & $34(9.3)$ & $14(15.4)$ & $20(7.3)$ & 0.04 \\
\hline NYHA class & & & & 0.40 \\
\hline I & $74(20.3)$ & $21(23.1)$ & $53(19.3)$ & \\
\hline$\|$ & $220(60.3)$ & $51(56.0)$ & $169(61.7)$ & \\
\hline III & $71(19.4)$ & $19(20.9)$ & $52(19.0)$ & \\
\hline Alcohol, current & $158(43.3)$ & $43(47.3)$ & $115(42.0)$ & 0.40 \\
\hline Smoking, current & $155(42.5)$ & $44(48.4)$ & $111(40.5)$ & 0.22 \\
\hline Diabetes & $80(21.9)$ & $26(28.6)$ & $54(19.7)$ & 0.08 \\
\hline Hypertension & $144(39.5)$ & $42(46.2)$ & $102(37.2)$ & 0.14 \\
\hline Dyslipidemia & $53(14.5)$ & $21(23.1)$ & $32(11.7)$ & 0.01 \\
\hline Prior Ml & $63(17.3)$ & $16(17.6)$ & $47(17.2)$ & 1.00 \\
\hline Prior PCl & $54(14.8)$ & $15(16.5)$ & $39(14.2)$ & 0.61 \\
\hline Prior CABG & $37(10.1)$ & $10(11.0)$ & $27(9.9)$ & 0.84 \\
\hline Prior Stroke & $31(8.5)$ & $7(7.7)$ & $24(8.8)$ & 0.83 \\
\hline Chronic renal disease & $21(5.8)$ & $5(5.5)$ & $16(5.8)$ & 1.00 \\
\hline \multicolumn{5}{|l|}{ Atrial fibrillation } \\
\hline Paroxysmal & $88(24.1)$ & $25(27.5)$ & $63(23.0)$ & 0.40 \\
\hline Persistent & $17(4.7)$ & $4(4.4)$ & $13(4.7)$ & 1.00 \\
\hline Permanent & $1(0.3)$ & $0(0.0)$ & $1(0.4)$ & 1.00 \\
\hline LVEF (\%) & $38.4 \pm 15.70$ & $34.7 \pm 14.67$ & $39.7 \pm 15.86$ & 0.01 \\
\hline \multicolumn{5}{|l|}{ Etiology } \\
\hline Idiopathic VT/VF & $89(24.4)$ & - & $89(24.4)$ & $<0.001$ \\
\hline Coronary artery disease & $89(24.4)$ & $24(26.4)$ & $65(23.7)$ & 0.67 \\
\hline Dilated CMP & $97(26.6)$ & $42(46.2)$ & $55(20.1)$ & $<0.001$ \\
\hline Hypertrophic CMP & $48(13.2)$ & $17(18.7)$ & $31(11.3)$ & 0.08 \\
\hline Restricted CMP & $2(0.7)$ & - & $2(0.7)$ & 1.00 \\
\hline ARVD/C & $9(2.5)$ & $3(3.3)$ & $6(2.2)$ & 0.70 \\
\hline Valvular heart disease & $13(3.6)$ & $1(1.1)$ & $12(4.4)$ & 0.20 \\
\hline Brugada syndrome & $19(5.2)$ & $3(3.3)$ & $16(5.8)$ & 0.43 \\
\hline Long QT syndrome & $4(1.1)$ & $0(0.0)$ & $4(1.5)$ & 0.58 \\
\hline Ebstein's anomaly & $2(0.5)$ & $1(1.1)$ & $1(0.4)$ & 0.44 \\
\hline Miscellaneous & $6(1.7)$ & $1(1.1)$ & $5(1.8)$ & 0.98 \\
\hline
\end{tabular}


Table 1. Baseline characteristics of patients

\begin{tabular}{lcccc}
\hline & $\begin{array}{c}\text { Total } \\
(\mathrm{n}=365)\end{array}$ & $\begin{array}{c}\text { Primary prevention } \\
(\mathrm{n}=91)\end{array}$ & $\begin{array}{c}\text { Secondary prevention } \\
(\mathrm{n}=274)\end{array}$ & $P$-value \\
\hline $\begin{array}{l}\text { Medication on discharge } \\
\text { Beta-blocker }\end{array}$ & & & & \\
ACEi/ARB & $230(63.0)$ & $68(74.7)$ & $162(59.1)$ & 0.01 \\
Spironolacton & $170(46.6)$ & $56(61.5)$ & $114(41.6)$ & 0.001 \\
Loop diuretics & $81(22.2)$ & $36(39.6)$ & $45(16.4)$ & $<0.001$ \\
Statin & $124(34.0)$ & $42(46.2)$ & $82(29.9)$ & 0.01 \\
Antiplatelet & $130(35.6)$ & $35(38.5)$ & $95(34.7)$ & 0.53 \\
Anticoagulant & $114(31.2)$ & $33(36.3)$ & $81(29.6)$ & 0.24 \\
Antiarrhythmic & $66(18.1)$ & $22(24.2)$ & $44(16.1)$ & 0.09 \\
\hline
\end{tabular}

Values are mean \pm standard deviation or $n(\%)$.

ACEi/ARB indicates angiotensin converting enzyme inhibitor or aldosterone receptor blocker; ARVD/C, arrhythmogenic right ventricular dysplasia or cardiomyopathy; BMI, body mass index; CABG, coronary artery bypass graft surgery; CMP, cardiomyopathy; LVEF, left ventricular ejection fraction; MI, myocardial infarction; PCl, percutaneous coronary intervention; NYHA class, New York Heart Association functional class; SCD, sudden cardiac death; VTNF, ventricular tachycardia or fibrillation
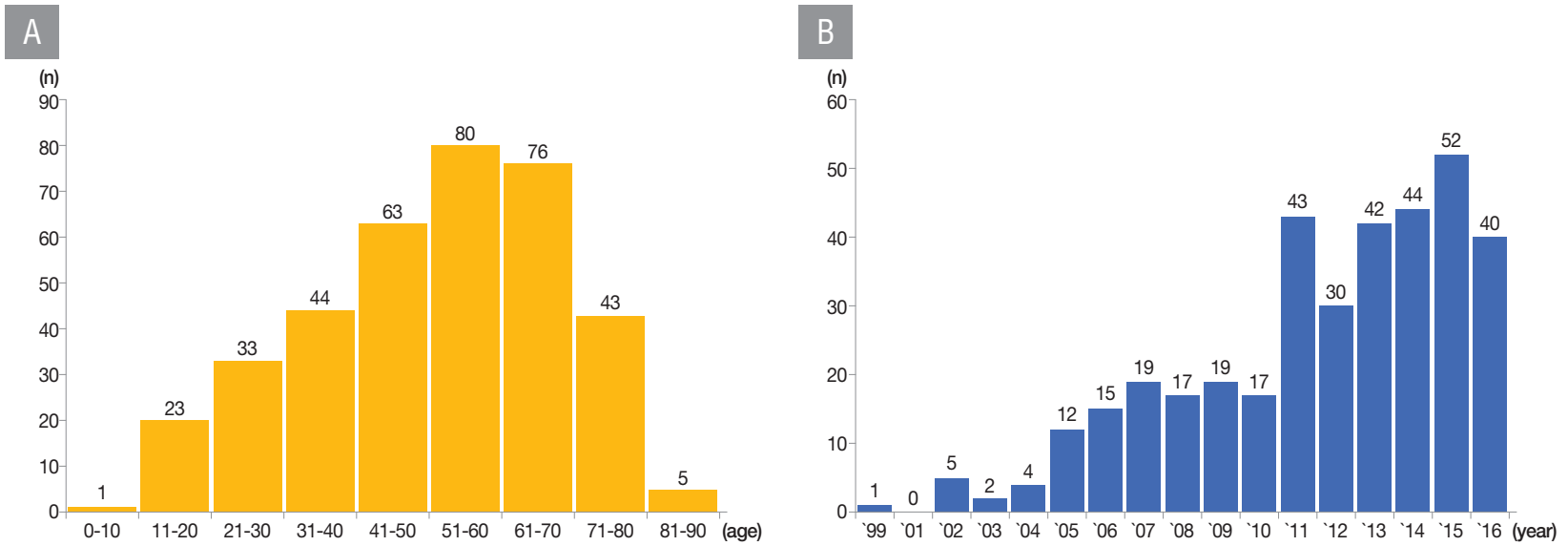

Figure 2. Distribution of patients according to the $(A)$ age and $(B)$ the year of procedure

\section{Device-related characteristics}

Table 2 shows the device-related characteristics. The commercial devices by four manufacturers are available in Korea. A total of 15 patients (4.1\%) were implanted with ICD generator at their right sides, 4 of whom experienced shock events, and all shock delivery could terminate tachyarrhythmia. Dual-chamber ICD was implanted in $16.5 \%$ and $8.0 \%$ of patients with ICD for primary and secondary prevention. One zone therapy setting was the most prevalent in the primary and secondary prevention groups $(51.6 \%$ and $64.6 \%$, respectively). The proportion of cases, which turn on the therapy for all three zones, was $3.8 \%$ of the entire population. The average of the minimum heart rate to recognize VF zone was $208.43 \pm 15.24 \mathrm{bpm}$ in the primary prevention group and $201.96 \pm 12.89 \mathrm{bpm}$ in the secondary prevention group. The VT2 zone was set as ATP + shock therapy for $61.4 \%$ and $41.2 \%$ of the primary and secondary prevention groups, respectively. The VT1 zone was set to monitor only in $91.7 \%$ of the primary prevention group and $74.6 \%$ of the secondary prevention group. As going down from the VF zone to VT1 zone, the total number of shock and minimum shock joules that could actually terminate the tachyarrhythmia tended to decrease. 
Table 2. ICD-related parameters

\begin{tabular}{|c|c|c|c|c|}
\hline & $\begin{array}{c}\text { Total } \\
(\mathrm{n}=365)\end{array}$ & $\begin{array}{l}\text { Primary prevention } \\
\qquad(\mathrm{n}=91)\end{array}$ & $\begin{array}{l}\text { Secondary prevention } \\
(n=274)\end{array}$ & $P$-value \\
\hline Manufacturer & & & & 0.004 \\
\hline St. Jude Medical & $177(48.5)$ & $34(37.4)$ & 143 (52.2) & \\
\hline Medtronic & $108(29.6)$ & $30(33.0)$ & $78(28.5)$ & \\
\hline Biotronik & $31(8.5)$ & $16(17.6)$ & $15(5.5)$ & \\
\hline Boston Scientific & $49(13.4)$ & $11(12.1)$ & 38 (13.8) & \\
\hline No. of lead & & & & 0.03 \\
\hline Single chamber & $328(89.9)$ & $76(83.5)$ & $252(92.0)$ & \\
\hline Dual chamber & 37 (10.1) & $15(16.5)$ & $22(8.0)$ & \\
\hline No. of shock coil & & & & 0.11 \\
\hline Single coil & $150(41.1)$ & $44(48.4)$ & $106(38.7)$ & \\
\hline Dual coil & $215(58.9)$ & $47(51.6)$ & $168(61.3)$ & \\
\hline Generator position & & & 1.00 & \\
\hline Left side & $350(95.9)$ & $87(95.6)$ & $263(96.0)$ & $>0.999$ \\
\hline Right side & $15(4.1)$ & $4(4.4)$ & $11(4.0)$ & \\
\hline Therapy zone & & & & 0.03 \\
\hline One zone & $224(61.4)$ & $47(51.6)$ & $177(64.6)$ & \\
\hline Two zone & $127(34.8)$ & $42(46.2)$ & $85(31.0)$ & \\
\hline Three zone & $14(3.8)$ & $2(2.2)$ & $12(4.4)$ & \\
\hline \multicolumn{5}{|l|}{ VF zone } \\
\hline Status: on & $365(100)$ & $91(100)$ & $274(100)$ & 1.00 \\
\hline Cycle length (msec) & $296.14 \pm 19.90$ & $289.35 \pm 20.88$ & $298.39 \pm 19.08$ & $<0.001$ \\
\hline Heart rate (bpm) & $203.57 \pm 13.78$ & $208.43 \pm 15.24$ & $201.96 \pm 12.89$ & $<0.001$ \\
\hline No. of shock & $6.14 \pm 0.61$ & $6.36 \pm 0.80$ & $6.07 \pm 0.51$ & $<0.001$ \\
\hline Minimum shock (J) & $28.73 \pm 4.89$ & $29.52 \pm 4.91$ & $28.46 \pm 4.87$ & 0.10 \\
\hline Maximum shock (J) & $36.57 \pm 2.32$ & $36.96 \pm 2.31$ & $36.45 \pm 2.31$ & 0.53 \\
\hline \multicolumn{5}{|l|}{ VT2 zone } \\
\hline Status: on & $210(57.5)$ & $57(62.6)$ & $153(55.8)$ & 0.27 \\
\hline Cycle length (msec) & $341.28 \pm 19.482$ & $343.30 \pm 24.49$ & $340.53 \pm 17.29$ & 0.92 \\
\hline Heart rate (bpm) & $176.36 \pm 8.976$ & $175.91 \pm 9.73$ & $176.52 \pm 8.71$ & 0.82 \\
\hline Shock only & $10(4.8)$ & $3(5.3)$ & $7(4.6)$ & 1.00 \\
\hline ATP + shock & $98(46.7)$ & $35(61.4)$ & $63(41.2)$ & 0.01 \\
\hline ATP only & $4(1.9)$ & $3(5.3)$ & $1(0.7)$ & 0.06 \\
\hline Monitor only & $98(46.7)$ & $16(28.1)$ & $82(53.6)$ & 0.001 \\
\hline No. of shock & $5.06 \pm 1.65$ & $5.61 \pm 1.73$ & $4.76 \pm 1.53$ & 0.01 \\
\hline Minimum shock (J) & $24.84 \pm 7.08$ & $26.42 \pm 6.21$ & $23.99 \pm 7.42$ & 0.16 \\
\hline Maximum shock (J) & $36.83 \pm 2.81$ & $37.76 \pm 2.41$ & $36.33 \pm 2.90$ & 0.02 \\
\hline No. of ATP & $2.63 \pm 1.19$ & $2.84 \pm 1.24$ & $2.50 \pm 1.16$ & 0.11 \\
\hline
\end{tabular}


Table 2. ICD-related parameters

\begin{tabular}{lcccc}
\hline & $\begin{array}{c}\text { Total } \\
(\mathrm{n}=365)\end{array}$ & $\begin{array}{c}\text { Primary prevention } \\
(\mathrm{n}=91)\end{array}$ & $\begin{array}{c}\text { Secondary prevention } \\
(\mathrm{n}=274)\end{array}$ & $P$-value \\
\hline VT1 zone & & & & \\
$\quad$ Status: on & $202(55.3)$ & $60(65.9)$ & $142(51.8)$ & 0.02 \\
Cycle length (msec) & $397.54 \pm 28.61$ & $400.83 \pm 41.29$ & $396.15 \pm 21.14$ & 0.81 \\
Heart rate (bpm) & $151.73 \pm 8.08$ & $152.17 \pm 9.52$ & $151.55 \pm 7.42$ & 0.73 \\
Shock only & $3(1.5)$ & $0(0.0)$ & $3(2.1)$ & 0.56 \\
ATP + shock & $33(16.3)$ & $5(8.3)$ & $28(19.7)$ & 0.06 \\
ATP only & $5(2.5)$ & $0(0.0)$ & $5(3.5)$ & 0.33 \\
Monitor only & $161(79.7)$ & $55(91.7)$ & $106(74.6)$ & 0.01 \\
No. of shock & $4.14 \pm 0.76$ & $4.20 \pm 0.45$ & $4.13 \pm 0.81$ & 0.74 \\
Minimum shock (J) & $20.00 \pm 9.50$ & $19.00 \pm 6.52$ & $20.16 \pm 9.96$ & 0.69 \\
Maximum shock $(\mathrm{J})$ & $34.49 \pm 6.56$ & $35.60 \pm 0.55$ & $34.31 \pm 7.06$ & 0.80 \\
No. of ATP & $2.95 \pm 2.69$ & $2.40 \pm 1.14$ & $3.03 \pm 2.84$ & 0.77 \\
\hline
\end{tabular}

Values are mean \pm standard deviation or $n(\%)$.

ATP, anti-tachycardia pacing; VT, ventricular tachycardia; VF, ventricular fibrillation

\section{Clinical outcomes}

The median follow-up period was 3.1 years (interquartile range: $1.6-6.0$ years). The outcome data were compared based on the baseline etiology of heart failure and purpose of ICD implantation. The results were described in Table 3 . The primary outcome was noted in $28.6 \%$ and $33.2 \%$ of patients with ICD for primary and secondary prevention, respectively $(p=0.44)$. The survival rate from the primary outcome was not significantly different between these patients (log-rank $p=0.87$, Figure 3). Among the patients with ICD for primary prevention, 2 patients (2.2\%) died because of cardiac nonischemic cause. In contrast, among patients with ICD for secondary prevention, cardiac death was noted in 5 patients $(1.8 \%, 3$ and 2 because of nonischemic and ischemic causes, respectively). The survival rate from cardiac death was not significantly different between patients with ICD for primary and secondary prevention with respect to purpose and etiology (Figure 4A). The rate of hospitalization because of heart failure was higher in patients with ICD for primary prevention than in those for secondary prevention (23.1\% versus $13.5 \%, p=0.03$ ). Hospitalization because of heart failure was more prevalent in the ischemic group than in the nonischemic group

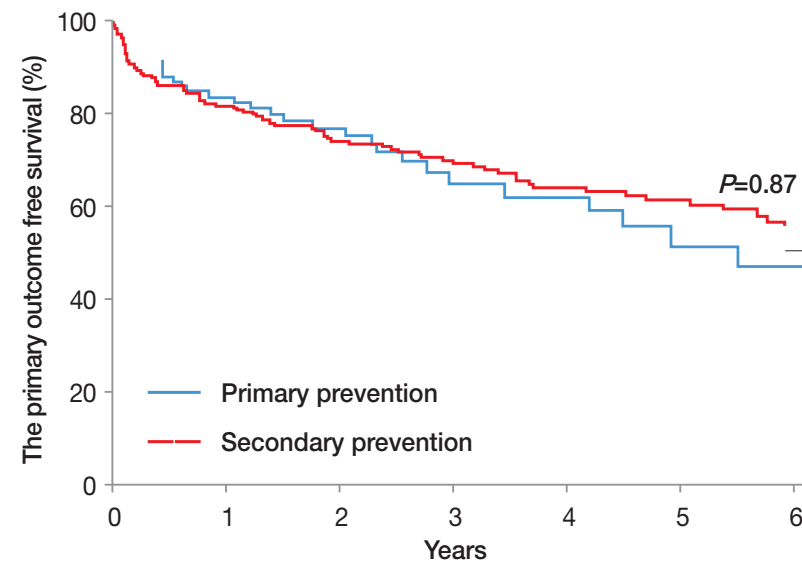

Figure 3. Comparison of primary outcome free survival curves among the patient $s$ with ICD implantation for primary or secondary prevention. The table below shows cumulative number with rate of event.

ICD, implantable cardioverter defibrillator

with ICD for secondary prevention (10.5\% versus $23.0 \%$, $p=0.01$ ). The hospitalization-free survival rate was significantly higher in the nonischemic group with ICD for secondary prevention than in other groups (log-rank $p=0.01$, Figure $4 \mathrm{~B}$ ). Heart transplantation was performed in $7.7 \%$ and $4.7 \%$ of patients with ICD for primary and secondary prevention, respectively. 
Table 3. Clinical outcomes depending on primary or secondary prevention

\begin{tabular}{|c|c|c|c|c|c|c|c|c|c|}
\hline & \multicolumn{4}{|c|}{ Primary prevention } & \multicolumn{4}{|c|}{ Secondary prevention } & \multirow[b]{2}{*}{$P$-valuell } \\
\hline & $\begin{array}{c}\text { Non-Ischemic } \\
(n=67)\end{array}$ & $\begin{array}{l}\text { Ischemic } \\
(n=24)\end{array}$ & $\begin{array}{c}\text { Total } \\
(n=91)\end{array}$ & $P$-value ${ }^{\S}$ & $\begin{array}{c}\text { Non-Ischemic } \\
(\mathrm{n}=209)\end{array}$ & $\begin{array}{l}\text { Ischemic } \\
(n=65)\end{array}$ & $\begin{array}{c}\text { Total } \\
(n=274)\end{array}$ & $P$-value $\S$ & \\
\hline Primary outcome* & $19(28.4)$ & $7(29.2)$ & $26(28.6)$ & 1.00 & $67(32.1)$ & $24(36.9)$ & $91(33.2)$ & 0.55 & 0.44 \\
\hline \multicolumn{10}{|l|}{ Secondary outcome } \\
\hline All-cause death & $5(7.5)$ & - & $5(5.5)$ & 0.32 & $11(5.3)$ & $7(10.8)$ & $18(6.6)$ & 0.15 & 0.81 \\
\hline Cardiac death & $2(3.0)$ & - & $2(2.2)$ & 1.00 & $3(1.4)$ & $2(3.1)$ & $5(1.8)$ & 0.34 & 1.00 \\
\hline Heart failure admission & $14(20.9)$ & $7(29.2)$ & $21(23.1)$ & 0.41 & $22(10.5)$ & $15(23.1)$ & $37(13.5)$ & 0.01 & 0.03 \\
\hline Heart transplantation & $6(9.0)$ & $1(4.2)$ & $7(7.7)$ & 0.67 & $12(5.7)$ & $1(1.5)$ & $13(4.7)$ & 0.31 & 0.29 \\
\hline Pocket Infection & $2(3.0)$ & - & $2(2.2)$ & 1.00 & $8(3.8)$ & $2(3.1)$ & $10(3.6)$ & 1.00 & 0.74 \\
\hline \multicolumn{10}{|l|}{ Appropriate therapy } \\
\hline Shock & $16(23.9)$ & $4(16.7)$ & $20(22.0)$ & 0.57 & $54(25.8)$ & $22(33.8)$ & $76(27.7)$ & 0.21 & 0.34 \\
\hline ATP & $10(14.9)$ & $6(25.0)$ & $16(17.6)$ & 0.35 & $33(15.8)$ & $20(30.8)$ & $53(19.3)$ & 0.01 & 0.76 \\
\hline No. of shock ${ }^{\dagger}$ & $1.07 \pm 3.32$ & $0.33 \pm 1.05$ & $0.88 \pm 2.91$ & 0.39 & $2.78 \pm 11.54$ & $2.78 \pm 6.96$ & $2.78 \pm 10.62$ & 0.18 & 0.17 \\
\hline No. of ATP $\ddagger$ & $2.36 \pm 8.25$ & $0.54 \pm 1.10$ & $1.88 \pm 7.14$ & 0.39 & $3.93 \pm 25.52$ & $9.74 \pm 32.96$ & $5.31 \pm 27.52$ & 0.01 & 0.63 \\
\hline \multicolumn{10}{|l|}{ Inappropriate therapy } \\
\hline Shock & $8(11.9)$ & $4(16.7)$ & $12(13.2)$ & 0.73 & $35(16.7)$ & $13(20.0)$ & $48(17.5)$ & 0.58 & 0.42 \\
\hline by AF/AFL & $5(62.5)$ & $3(75.0)$ & $8(66.7)$ & 1.00 & $20(57.1)$ & $8(61.5)$ & $28(58.3)$ & 1.00 & 0.75 \\
\hline by SVT & $2(25.0)$ & $1(25.0)$ & $3(25.0)$ & 1.00 & $11(31.4)$ & $5(38.5)$ & $16(33.3)$ & 0.74 & 0.74 \\
\hline by Inappropriate sensing & $1(12.5)$ & - & $1(8.3)$ & 1.00 & $4(11.4)$ & - & $4(8.3)$ & 0.56 & 1.00 \\
\hline ATP & $3(4.5)$ & $2(8.3)$ & $5(5.5)$ & 0.60 & $14(6.7)$ & $11(16.9)$ & $25(9.1)$ & 0.02 & 0.38 \\
\hline No. of shock ${ }^{\dagger}$ & $0.42 \pm 1.60$ & $1.08 \pm 3.30$ & $0.59 \pm 2.18$ & 0.51 & $0.76 \pm 2.54$ & $0.52 \pm 1.38$ & $0.70 \pm 2.32$ & 0.61 & 0.36 \\
\hline No. of ATP $\ddagger$ & $0.99 \pm 7.46$ & $0.67 \pm 3.06$ & $0.90 \pm 6.57$ & 0.49 & $0.40 \pm 2.03$ & $1.17 \pm 5.13$ & $0.58 \pm 3.06$ & 0.01 & 0.28 \\
\hline
\end{tabular}

Values are mean \pm standard deviation or $n(\%)$.

- Primary outcome was defined as a composite of cardiac death, appropriate shock or appropriate anti-tachycardia pacing.

+ Number of shock means average count of shock per a person.

₹ Number of ATP means average count of anti-tachycardia pacing per a person.

$\S$ Comparison between non-ischemic group and ischemic group

"Comparison between primary prevention group and secondary prevention group

AF/AFL, atrial fibrillation or flutter; ATP, anti-tachycardia pacing; SVT, supraventricular tachycardia

\section{ICD therapy}

A total of 134 patients $(36.7 \%)$ underwent ICD therapy, of whom 60 (44.8\%) had experienced inappropriate shock. The most common cause of inappropriate shock was AF/AFL (66.7\% and $58.3 \%$ of the primary and secondary prevention groups, respectively). The rates of appropriate shock and inappropriate shock were not significantly different with respect to the etiology and purpose (Figure 4C and Figure 4D). Patients with ICD for primary and secondary prevention had a mean number of shock events of $0.88 \pm 2.91$ and $2.78 \pm 10.62$, respectively, with the difference being not significant. The mean number of shock events based on the etiology was also not different.

\section{Independent risk factors}

Table 4 shows the independent risk factors to predict the 
A

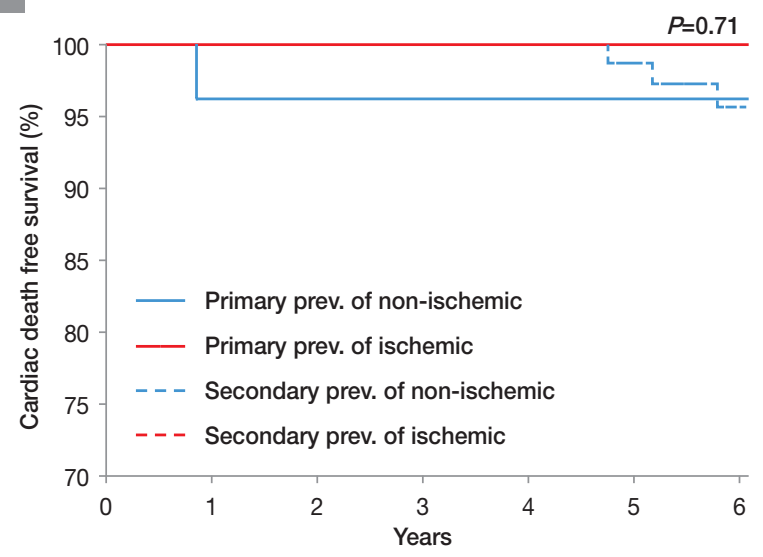

C

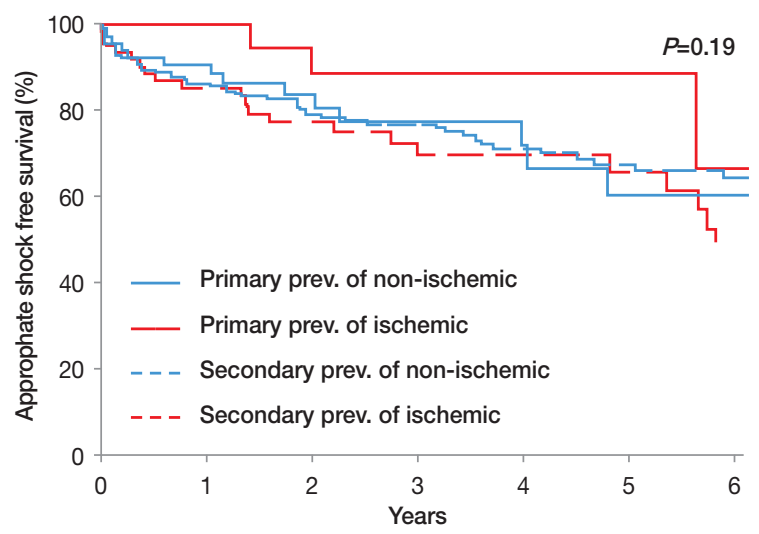

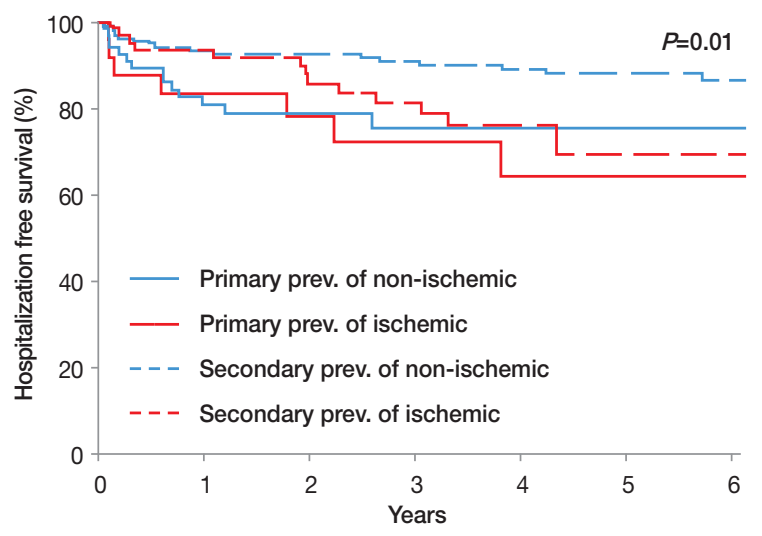

D

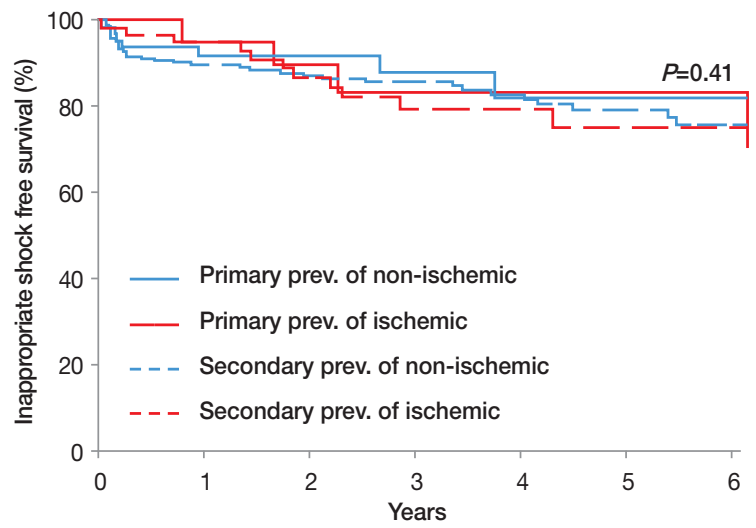

Figure 4. Comparison of survival curves among the patients' groups depending on the etiology or the purpose for ICD implantation. (A) Cardiac death free survival, (B) hospitalization free survival, (C) appropriate shock free survival, and (D) inappropriate shock free survival.

ICD, implantable cardioverter defibrillator; prev, prevention

primary outcome. NYHA functional class (hazard ratio [HR], 21.05; 95\% confidence interval [CI], 4.22-104.94; $p<0.001)$, permanent AF (HR, 22.07; 95\% CI, 2.93-166.41; $p<0.001)$, previous history of SCD (HR, 0.66; 95\% CI, 0.45-0.96; $p=0.03$ ), and Ebstein's anomaly (HR, 5.08; 95\% CI, 1.2420.76; $p=0.02$ ) were associated with an increased risk of primary outcome in univariate analysis. Among them, after multivariate adjustment, NYHA functional class (adjusted HR, 20.45; 95\% CI, 4.01-95.42; $p<0.01$ ), permanent AF (adjusted HR, 21.94; 95\% CI, 2.55-188.80; $p=0.01$ ), and Ebstein's anomaly (adjusted HR, 5.31; 95\% CI, 1.30-21.71; $p=0.02$ ) were consistently associated with an increased risk of primary outcome.

\section{Discussion}

The major findings of the study were that dilated CMP and idiopathic VT/VF were the most common etiologies for ICD implantation for primary and secondary prevention, respectively, and that coronary artery disease was the second most common. The implantation rate was much higher in men than in women. About one-third of patients undergoing ICD implantation had AF. Dual-chamber ICD system had been inserted in one-tenth of patients. The rates of cardiac death and heart transplantation were not significantly different between the two groups regardless of etiology and purpose. The rate of hospitalization because of heart failure was significantly higher in patients with ICD for primary 
Table 4. Independent risk factors to predict primary outcome

\begin{tabular}{|c|c|c|c|c|}
\hline & \multicolumn{2}{|c|}{ Univariate analysis } & \multicolumn{2}{|c|}{ Multivariate analysis } \\
\hline & HR (95\% Cl) & $P$-value & Adjusted HR (95\% Cl) & $P$-value \\
\hline Male & $1.24(0.75-2.05)$ & 0.40 & $1.27(0.73-2.21)$ & 0.41 \\
\hline Age & $1.00(0.99-1.01)$ & 0.76 & $0.99(0.98-1.01)$ & 0.26 \\
\hline BMI & $1.04(0.99-1.09)$ & 0.09 & $1.02(0.97-1.08)$ & 0.40 \\
\hline Alcohol, current & $0.96(0.67-1.39)$ & 0.84 & $0.95(0.61-1.49)$ & 0.82 \\
\hline Smoking, current & $0.90(0.62-1.30)$ & 0.58 & $0.86(0.55-1.35)$ & 0.51 \\
\hline NYHA class & $21.05(4.22-104.94)$ & $<0.001$ & $20.45(4.01-95.42)$ & $<0.01$ \\
\hline Diabetes & $1.15(0.74-1.79)$ & 0.54 & $1.02(0.62-1.69)$ & 0.93 \\
\hline Hypertension & $1.11(0.77-1.610$ & 0.58 & $1.04(0.66-1.63)$ & 0.87 \\
\hline Dyslipidemia & $0.95(0.54-1.67)$ & 0.86 & $0.90(0.50-1.63)$ & 0.73 \\
\hline Chronic renal disease & $0.93(0.38-2.28)$ & 0.87 & $0.94(0.37-2.42)$ & 0.90 \\
\hline Permanent AF & $22.07(2.93-166.41)$ & $<0.001$ & $21.94(2.55-188.80)$ & 0.01 \\
\hline LV ejection fraction & $1.00(0.99-1.01)$ & 0.72 & $1.00(0.99-1.02)$ & 0.79 \\
\hline History of cardiac arrest & $0.66(0.45-0.96)$ & 0.03 & $0.65(0.40-1.04)$ & 0.07 \\
\hline Secondary prevention & $1.04(0.67-1.61)$ & 0.87 & $1.38(0.85-2.22)$ & 0.19 \\
\hline Idiopathic VT/VF & $0.75(0.48-1.16)$ & 0.19 & $1.29(0.59-2.80)$ & 0.52 \\
\hline Coronary artery disease & $1.13(0.75-1.71)$ & 0.56 & $1.62(0.70-3.74)$ & 0.26 \\
\hline Dilated CMP & $1.42(0.95-2.12)$ & 0.09 & $1.99(0.90-4.42)$ & 0.09 \\
\hline Hypertrophic CMP & $0.95(0.56-1.61)$ & 0.85 & $1.19(0.50-2.83)$ & 0.69 \\
\hline Ebstein's anomaly & $5.08(1.24-20.76)$ & 0.02 & $5.31(1.30-21.71)$ & 0.02 \\
\hline
\end{tabular}

AF indicates atrial fibrillation; BMI, body mass index; Cl, confidence interval; CMP, cardiomyopathy; HR, hazard ratio; LV, left ventricle; NYHA, New York heart association; VT/NF, ventricular tachycardia or fibrillation.

prevention than in those for secondary prevention. The prevalence of appropriate shock and inappropriate shock was also not different between these patients. AF/AFL and SVT were the first and second most common causes of inappropriate shock, respectively. The independent risk factors for primary composite outcome were advanced NYHA functional class, permanent AF, and Ebstein's anomaly.

The increasing pattern in the ICD implantation procedures over a 17-year study period is similar to that in other studies in the same periods. ${ }^{12,13}$ However, the increasing rate of annual implantation is smaller than that in other studies probably because of different conditions of countries such as insurance regulations. In this study, the implantation rate in men was much higher than in women, and the finding is consistent with overserved in the USA and Europe. ${ }^{13-15}$ Several factors are found to produce sex difference in the use of ICD. Curtis et al. analyzed the reason in their study and suggested that, at the presentation of disease, women tend to be older than men and the physicians have been less likely to recommend ICD implantation. ${ }^{14}$ According to current guidelines, ICD therapy is recommended 
in the patients expected survival more than 1 year with good functional status. ${ }^{67}$ Our study showed that the ICD implantation rate was the highest in the 50 s, which may explain why most patients are male.

The beneficial effects of ICD therapy have been well established in primary and secondary prevention. ${ }^{3,16,17}$ However, studies comparing the potential difference between both groups are limited. Van Welsenes et al. reported that the 5-year cumulative incidence of all-cause death was $25 \%$ for primary prevention patients and $23 \%$ for secondary prevention patients. ${ }^{18}$ Secondary prevention was associated with an increased risk of appropriate therapy with a hazard ratio of 1.7 when compared with primary prevention in their registry. It is difficult to compare directly because the shock therapy is associated with device settings and medications. Our study also shows that secondary prevention tends to be a more experience appropriate therapy. A relatively short follow-up period and a low incidence rate may be the reasons for the decrease in statistical significance.

In the Multicenter Automatic Defibrillator Implantation Trial (MADIT) II, inappropriate shocks commonly occurred in $11.5 \%$ of patients, and the cumulative rate increased by $10 \%$ at 1 year and $13 \%$ at 2 years. ${ }^{19}$ AF was the most common cause, accounting for $44 \%$ of inappropriate shocks in this study. In our study, $13.2 \%$ and $17.5 \%$ of patients with ICD for primary and secondary prevention experienced inappropriate shock. The percentage of patients with AF/AFL causing inappropriate shock was higher than that in MADIT II ( $66.7 \%$ and $58.3 \%$ of patients with ICD for primary and secondary prevention). In the Pain-Free Study, $15 \%$ of patients experienced inappropriate therapy and showed a higher trend in the primary prevention group than in the secondary prevention group ( $46 \%$ versus $34 \%, p=0.09$ ). ${ }^{20}$ However, in our study, no difference was observed in the proportion of inappropriate shock according to the purpose of $\operatorname{ICD}(37.5 \%$ in the primary prevention group versus $38.7 \%$ in the secondary prevention group).

Although many strategies for minimizing inappropriate therapy have been suggested, no clear method is available. According to the data of Daubert et al., more aggressive use of the available SVT discriminators could reduce the incidence of inappropriate therapy. ${ }^{19}$ However, the information about stability or sudden onset was not available in our registry, and we could not analyze their effect. Dual-chamber ICD systems are commonly used to reduce the inappropriate therapy. The Detect Supraventricular Tachycardia Study reported a reduction of inappropriate detection in the dual-chamber system (30.9\%) compared with that of the single-chamber system (39.5\%). However, several conflicting studies exist about the benefit of dual-chamber system. ${ }^{21,22}$ In our study, $10.8 \%$ of patients with the dual-chamber ICD system experienced inappropriate shock, and the incidence was not significantly reduced compared with that of the single-chamber system (17.1\%).

\section{Study limitations}

This study has several limitations. First, all parameters were based on the initial setting. As the patient's condition changed or many patients experienced ICD shock events, the parameters related to ICD therapy were changed in some patients. The changes of the ICD parameters could not be analyzed in a timedependent fashion. Second, the electrocardiogram interpretation to decide the suitability of the therapy was based on only available data. In some patients, missing electrocardiogram could not be confirmed the arrhythmia triggered therapy. Third, some unrecorded data on the registry could not be analyzed. For example, we could not get the data for stability and sudden-onset programming on the electronic medical record in a significant number of patients.

\section{Conclusion}

The most common etiologies for ICD implantation were dilated CMP and idiopathic VT/VF in patients with ICD for primary and secondary prevention, respectively. Inappropriate shocks were caused most commonly by AF/AFL. The incidence of composite outcomes of cardiac death, appropriate shock, or ATP was not significantly different between patients with ICD for primary and secondary prevention with respect to etiology or purpose. The independent risk factors for primary outcome were advanced NYHA functional class, permanent AF, and Ebstein's anomaly. The clinical efficacy and safety of ICD in Korean 
patients are consistent with the data from studies conducted in patients from Western countries.

\section{References}

1) Turakhia M, Tseng $Z H$. Sudden cardiac death: epidemiology, mechanisms, and therapy. Curr Probl Cardiol. 2007;32:501-546.

2) Moss AJ, Hall WJ, Cannom DS, Daubert JP, Higgins SL, Klein H, Levine JH, Saksena S, Waldo AL, Wilber D, Brown MW, Heo M. Improved survival with an implanted defibrillator in patients with coronary disease at high risk for ventricular arrhythmia. Multicenter Automatic Defibrillator Implantation Trial Investigators. N Engl J Med. 1996;335:1933-1940.

3) Antiarrhythmics versus Implantable Defibrillators (AVID) Investigators. A comparison of antiarrhythmic-drug therapy with implantable defibrillators in patients resuscitated from near-fatal ventricular arrhythmias. NEngl J Med. 1997;337:1576-1583.

4) Moss AJ, Zareba W, Hall WJ, Klein H, Wilber DJ, Cannom DS, Daubert JP, Higgins SL, Brown MW, Andrews ML; Multicenter Automatic Defibrillator Implantation Trial II Investigators. Prophylactic implantation of a defibrillator in patients with myocardial infarction and reduced ejection fraction. $N$ Engl J Med. 2002;346:877-883.

5) Al-Khatib SM, Hellkamp A, Bardy GH, Hammill S, Hall WJ, Mark DB, Anstrom KJ, Curtis J, Al-Khalidi H, Curtis LH, Heidenreich P, Peterson ED, Sanders G, Clapp-Channing N, Lee KL, Moss AJ. Survival of patients receiving a primary prevention implantable cardioverter-defibrillator in clinical practice vs clinical trials. Jama. 2013;309:55-62.

6) Epstein AE, DiMarco JP, Ellenbogen KA, Estes NA 3rd, Freedman RA, Gettes LS, Gillinov AM, Gregoratos G, Hammill SC, Hayes DL, Hlatky MA, Newby LK, Page RL, Schoenfeld MH, Silka MJ, Stevenson LW, Sweeney MO, Tracy CM, Epstein AE, Darbar D, DiMarco JP, Dunbar SB, Estes NA 3rd, Ferguson TB Jr, Hammill SC, Karasik PE, Link MS, Marine JE, Schoenfeld MH, Shanker AJ, Silka MJ, Stevenson LW, Stevenson WG, Varosy PD; American College of Cardiology Foundation; American Heart Association Task Force on Practice Guidelines; Heart Rhythm Society. 2012 ACCF/AHA/HRS focused update incorporated into the ACCF/ AHA/HRS 2008 guidelines for device-based therapy of cardiac rhythm abnormalities: a report of the American College of Cardiology Foundation/American Heart Association Task Force on Practice Guidelines and the Heart Rhythm Society. J Am Coll Cardiol. 2013;61:e6-75.

7) Epstein AE, DiMarco JP, Ellenbogen KA, Estes NA 3rd, Freedman RA, Gettes LS, Gillinov AM, Gregoratos G, Hammill SC, Hayes DL, Hlatky MA, Newby LK, Page RL, Schoenfeld MH, Silka MJ, Stevenson LW, Sweeney MO, Smith SC Jr, Jacobs AK, Adams CD, Anderson JL, Buller CE, Creager MA, Ettinger SM, Faxon DP, Halperin JL, Hiratzka LF, Hunt SA, Krumholz HM, Kushner FG, Lytle BW, Nishimura RA, Ornato JP, Page RL, Riegel B, Tarkington LG, Yancy CW; American College of Cardiology/ American Heart Association Task Force on Practice Guidelines (Writing Committee to Revise the ACC/AHA/NASPE 2002 Guideline Update for Implantation of Cardiac Pacemakers and Antiarrhythmia Devices); American Association for Thoracic Surgery; Society of Thoracic Surgeons. ACC/AHA/HRS 2008 guidelines for device-based therapy of cardiac rhythm abnormalities: a report of the American College of Cardiology/American Heart Association task force on practice guidelines (writing committee to revise the ACC/AHA/NASPE 2002 guideline update for implantation of cardiac pacemakers and antiarrhythmia devices) developed in collaboration with the American Association for thoracic surgery and society of thoracic surgeons. J Am Coll Cardiol. 2008;51:e1-62.

8) Uhm JS, Kim TH, Kim IC, Park YA, Shin DG, Lim YM, Yu HT, Yang PS, Pak HN, Kang SM, Lee MH, Joung B. Long-term prognosis of patients with an implantable cardioverter-defibrillator in Korea. Yonsei Med J. 2017;58:514-520.

9) Park KH, Lee CH, Jung BC, Cho Y, Bae MH, Kim YN, Park HS, Han S, Lee YS, Hyun DW, Kim J, Kim DK, Cha TJ, Shin DG. Effectiveness of implantable cardioverter-defibrillator therapy for heart failure patients according to ischemic or non-ischemic etiology in Korea. Korean Circ J. 2017; 47:72-81.

10) Swerdlow CD, Friedman PA. Advanced ICD troubleshooting: Part I. PACE. 2005;28:1322-1346.

11) Klein RC, Raitt MH, Wilkoff BL, Beckman KJ, Coromilas J, Wyse DG, Friedman PL, Martins JB, Epstein AE, Hallstrom AP, Ledingham RB, Belco KM, Greene HL; AVID Investigators. Analysis of implantable cardioverter defibrillator therapy in the Antiarrhythmics Versus Implantable Defibrillators (AVID) Trial. J Cardiovasc Electrophysiol. 2003;14:940-948.

12) Al-Khatib SM, Hellkamp AS, Hernandez AF, Fonarow GC, Thomas KL, Al-Khalidi HR, Heidenreich PA, Hammill S, Yancy C, Peterson ED; Get With the Guidelines Steering Committee 
and Hospitals. Trends in use of implantable cardioverterdefibrillator therapy among patients hospitalized for heart failure: have the previously observed sex and racial disparities changed over time? Circulation. 2012;125:1094-1101.

13) Schmidt M, Pedersen SB, Farkas DK, Hjortshøj SP, Bøtker HE, Nielsen JC, Sørensen HT. Thirteen-year nationwide trends in use of implantable cardioverter-defibrillators and subsequent longterm survival. Heart rhythm. 2015;12:2018-2027.

14) Curtis LH, Al-Khatib SM, Shea AM, Hammill BG, Hernandez AF, Schulman KA. Sex differences in the use of implantable cardioverter-defibrillators for primary and secondary prevention of sudden cardiac death. Jama. 2007:298:1517-1524.

15) Gauri AJ, Davis A, Hong T, Burke MC, Knight BP. Disparities in the use of primary prevention and defibrillator therapy among blacks and women. Am J Med. 2006;119:167 e17-21.

16) Goldenberg I, Gillespie J, Moss AJ, Hall WJ, Klein H, McNitt S, Brown MW, Cygankiewicz I, Zareba W; Executive Committee of the Multicenter Automatic Defibrillator Implantation Trial II. Long-term benefit of primary prevention with an implantable cardioverter-defibrillator: an extended 8-year follow-up study of the Multicenter Automatic Defibrillator Implantation Trial II. Circulation. 2010;122:1265-1271.

17) Kadish A, Dyer A, Daubert JP, Quigg R, Estes NA, Anderson KP, Calkins H, Hoch D, Goldberger J, Shalaby A, Sanders WE, Schaechter A, Levine JH; Defibrillators in Non-Ischemic Cardiomyopathy Treatment Evaluation (DEFINITE) Investigators. Prophylactic defibrillator implantation in patients with nonischemic dilated cardiomyopathy. $N$ Engl J Med.
2004;350:2151-2158.

18) van Welsenes GH, van Rees JB, Borleffs CJ, Cannegieter SC, Bax JJ, van Erven L, Schalij MJ. Long-term follow-up of primary and secondary prevention implantable cardioverter defibrillator patients. Europace. 2011;13:389-394.

19) Daubert JP, Zareba W, Cannom DS, McNitt S, Rosero SZ, Wang P, Schuger C, Steinberg JS, Higgins SL, Wilber DJ, Klein H, Andrews ML, Hall WJ, Moss AJ; MADIT II Investigators. Inappropriate implantable cardioverter-defibrillator shocks in MADIT II: frequency, mechanisms, predictors, and survival impact. J Am Coll Cardiol. 2008;51:1357-1365.

20) Sweeney MO, Wathen MS, Volosin K, Abdalla I, DeGroot PJ, Otterness MF, Stark AJ. Appropriate and inappropriate ventricular therapies, quality of life, and mortality among primary and secondary prevention implantable cardioverter defibrillator patients: results from the Pacing Fast VT REduces Shock ThErapies (PainFREE Rx II) trial. Circulation. 2005;111:2898905 .

21) Hintringer F, Schwarzacher S, Eibl G, Pachinger O. Inappropriate detection of supraventricular arrhythmias by implantable dual chamber defibrillators: a comparison of four different algorithms. PACE. 2001;24:835-841.

22) Deisenhofer I, Kolb C, Ndrepepa G, Schreieck J, Karch M, Schmieder S, Zrenner B, Schmitt C. Do current dual chamber cardioverter defibrillators have advantages over conventional single chamber cardioverter defibrillators in reducing inappropriate therapies? A randomized, prospective study. J Cardiovasc Electrophysiol. 2001;12:134-142. 